\title{
Los fragmentos de las historias de Salustio: su valor histórico
}

\author{
Narciso Santos Yanguas *
}

\begin{abstract}
RESUMEN ABSTRACT
En los fragmentos de las Historias de Salustio se analizan los rasgos que definen la crisis de la República romana desde el punto de vista institucional; en este contexto la actividad política de Sira se considera como el inicio de dicha decadencia. La expansión exterior se hallaría en el origen de la decadencia interna, destacando como elementos más significativos de la misma el enfrentamiento entre partidos, la corrupción de la sociedad, la ambigüedad de ciertos ciudadanos, el desarrollo de la avaricia y la ambición...

In the fragments from Salustio's Historiae an analysis is made on the aspects that explain the crisis, from an institutional point of view, of the Roman Republic; within this background, Sila's political activity is considered to be the starting point of such political decadence. Outward expansion would thus explain the origin of internal decadence, some of whose most significant features would be the clash between parties, the ambiguity of some citizens, social corruption, increasing avarice or even ambition...
\end{abstract}

Por desgracia la recopilación de la historia de Roma durante una etapa histórica ampliamente significativa, obra del escritor de Amiterno, únicamente se nos ha conservado en estado fragmentado, de manera que, al margen de ciertos pasajes enormemente cortos en su expresión y contenido (recogidos como tales en los códices y manuscritos palimpsestos), no

\footnotetext{
* Universidad de Oviedo.
} 
disponemos en la actualidad más que de los discursos seleccionados de los personajes más famosos de su época, entresacados del relato histórico de sus escritos ${ }^{1}$.

De cualquier forma nos permiten rastrear, si no el hilo conductor completo de la estructura y desarrollo de lo que fueron las Historias de Salustio, al menos los hitos históricos más importantes, en los que se verían involucrados los personajes romanos más significativos de la época (o Mitrídates en su comunicación al rey Arsaces) en el marco de esas décadas del siglo I a.n.e. en las que el Estado romano trataba, por un lado, de cerrar el ciclo de anexión de la cuenca mediterránea y, por otro, de poner fín a la lucha entre partidos a finales de la República.

De esta manera, en el momento en que nuestro historiador, una vez redactada La guerra de Yugurta, se hallaba en la plenitud y vigor de su talento literario, se entregó a la labor, ociosa pero fructífera a un mismo tiempo, de componer una obra de mayor envergadura y alcance, que, continuando la Historia de Sisena, se ocuparía de los 12 años de la historia de Roma que transcurrieron desde la muerte de Sila (año 78) hasta el 67 a.n.e. ${ }^{2}$.

¿Por qué razón elegiría Salustio ese período tan concreto de la evolución histórica de Roma? Tal vez porque sería en el transcurso de esos años cuando tuviera lugar el desarrollo de acontecimientos tan significativos para el Estado romano como la oposición a Sertorio en el marco de la guerra civil (años 80-72), la revuelta de esclavos encabezada por Espartaco (73-71), la guerra contra los piratas del Mediterráneo (78-67) y el comienzo del tercero de los enfrentamientos contra Mitrídates, rey del Ponto ${ }^{3}$.

Más difícil resulta tratar de comprender la interrupción brusca del relato de estos sucesos en el año 67, es decir en una fecha que a simple

\footnotetext{
- Esta serie de arengas y cartas se nos han transmitido bajo el título genérico de Excerpta, junto con las correspondientes a La conjuración de Catilina y La guerra de Yugurta, en el códice Vaticano 3864.

a Un pasaje del Yugurta (95.2) expresa claramente la intención de Salustio de no referirse a Sila, de quien había tratado ya Sisena. Sobre la extensión de las Historias cf. Ausonio, Epist. 22. 61-63, y Sal., Hist., fragm.1.1 M: Res populi Romani M.Lepido Q.Catulo consulibus ac deinde militiae et domi gestas composui.

3 Aspectos analizados ya desde inicios de este sigio por la historiografía contemporánea. Cf., por ejemplo, M. BONNET, "Les Histoires de Salluste; quels en devaient être le sujet et l'étendue», REA (1900) $117 \mathrm{ss}$.
} 
vista no marca ningún significado especial, por lo que quizás haya que buscar explicación a la misma en la prematura muerte del escritor ${ }^{4}$

Los hechos a que se refiere Salustio, así como los personajes involucrados en los mismos le ofrecen un material de base no solo amplio sino también variado en el marco de los objetivos que se proponía. Desgraciadamente esta obra no se ha conservado en su conjunto hasta nuestros días, teniendo conocimiento de la misma únicamente a través de una serie de fragmentos (discursos en su mayor parte), que en ningún caso permiten hacernos una idea acerca de su globalidad, si no es de manera parcial, y cuyo lugar en el contexto general de la misma no resulta fácil concretar ${ }^{5}$.

Los más destacados y significativos de dichos retazos literarios estan configurados por una serie de cartas y discursos, todos los cuales figuran en un manuscrito de Excerpta, conservado en nuestros días en el Vaticano (Vat.3864), y que contienen, por otro lado, los discursos y cartas entresacados igualmente de La conjuración de Catilina y de La guerra de Yugurta ${ }^{6}$.

A ello hemos de unir un grupo más de fragmentos contenidos en un manuscrito palimpsesto proveniente de la abadía de Fleury, que en la actualidad se conservan en Berlín y Orleans (Aurel. 169) ${ }^{7}$ : en tales documentos esta contenido, con lagunas, el relato correspondiente a los acontecimientos históricos más sobresalientes de los años 75-74 y, en especial, casi el contenido completo de la carta de Pompeyo que ya conocíamos por el manuscrito del Vaticano.

Junto a ello, dos hojas no palimpsestas de ese mismo manuscrito se encuentran igualmente conservadas en el Vaticano (Vat. Reg. 1283): en ellas aparecen registrados los inicios del relato de la revuelta de Espartaco. Todo ello sin desdeñar el hecho de que un grupo de escritores, historiadores, gramáticos y glosadores antiguos han conservado a lo largo de

\footnotetext{
4 A. Ennout, Salluste. Catilina, Jugurtha, Fragments des Historres, París 1974 (10. edic.), pág. 32.

5 Para más detalles remitimos, entre otros, a las conclusiones de $\mathrm{H}$. BLOCH, "The Structure of Sallusts Historiae. The Evidence of the Fleury Manuscript», Studia Albareda, Nueva York 1961, págs. 59 ss.

6 Todas estas cuestiones han sido tratadas ya ampliamente desde hace varias décadas. Ver, por ejemplo, entre otros, G. PERL, "Der alte Codex der Historiae Sallusts", BIRT 15 (1967-1968) 29 SS.; y E. LEPORE, "l due frammenti Rylands delle Storie di Sallustio", Athenaeum 28 (1950) 280 ss. Sobre el descubrimiento y desciframiento de los manuscritos referidos a esta obra de Salustio remitimos a A.D. LeEMAN, A Systematical Bibliography of Sallust (1879-1964), Leiden 1965, n.o 874-898.

7 E. PASOLI, «De orationibus atque epistulis de historiarum Sallusti libris excerptis», Acta Conv.lat.litt.ling.fov., Malta 1976, págs. 103 ss.
} 
los siglos en torno a 500 menciones, por lo general bastante escuetas, de esta importante obra de Salustio ${ }^{B}$.

Tradicionalmente se ha venido considerando que en las Historias se hallan reflejadas a la perfección las tendencias esenciales representadas en las dos monografías de Salustio, constituidas en el fondo por la polémica antinobiliaria, que se enfoca hacia la expansión de las clases dirigentes, asi como por la advertencia del peligro de subversión social que subyacía en aquellos momentos en la capital del Estado.

En realidad resulta evidente que ambos aspectos logran equilibrarse entre sí sin llegar a eliminarse en ningún momento del relato histórico, a pesar de que tampoco consigan unirse nunca en una verdadera síntesis política ${ }^{9}$.

Ahora bien, en principio resulta equivocado aplicar a esta obra salustiana los mismos parámetros de composición, estructura y desarrollo que serían utilizados en las monografías: parece mucho más lógico suponer que, a partir de la base representada por la práctica de la historiografía antigua, en especial tal y como se desarrolla entre los predecesores de Salustio, podemos encontrar ciertos puntos susceptibles de aclarar los métodos literarios y los recursos estilísticos que han sido aplicados en las Historias ${ }^{10}$.

Así, por ejemplo, en el prólogo de esta obra salustiana se rastrea una base menos sólida de los principios filosófico-literarios que en sus dos obras capitales conservadas (La conjuración de Catilina y La guerra de Yugurta); no obstante, se ha llegado a exagerar en ocasiones el pesimismo demostrado por el historiador en dicho preambulo, en especial en todo lo referente a su opinión y juicio crítico acerca de la juventud contemporánea ${ }^{11}$.

8 Sobre estos aspectos remitimos, por rejemplo, a A. LA PENNA, «Per la ricostruzione delle Historiae di Sallustio", RIFC 35 (1963) 5ss. En los últimos años se han descubierto algunos nuevos fragmentos: ver, entre otros, B. BISCHDFF y H. BLOCH, "Das Wiener Fragment der Historiae des Sallust (P. Vindob. L 117)», WS 13 (1979) 116 ss.

9 A. LA PENNA, "Le Historiae di Sallustio e l'interpretazione della crisi repubblicana», Athenaeum 41 (1966) $201 \mathrm{ss}$.

10 En estos aspectos ahonda preferentemente G. PERL, "Das Kompositionprinzip der Historiae des Sallust (zu Hist. fr.2.42)», Actes Xlle Conf.Eirene, Bucarest-Amsterdam 1975, págs. 317ss.

11 E. Castorina, "Sul proemio delie Historiae di Sallustio (fr.l,1-18 M.). La sentenziosità e il pesimismo», StudUrb 49.1 (1975) 355 ss. 
De esta manera la estructura del prólogo de las Historias no parece ofrecer las mismas características que la correspondiente a los de ambas monografías históricas de Salustio, cuyo temas y contenidos se encuentran muy próximos entre sí tanto en lo que se refiere a los planteamientos filosóficos como a los principios morales ${ }^{12}$.

Sin duda nuestro historiador no podía dejar de posicionarse en el debate de su época acerca de la mejor manera de escribir la historia, tema que apasionó a sus contemporáneos, y lo haría posiblemente tomando como punto de partida las opiniones de los historiadores que le habían precedido en el tiempo ${ }^{13}$.

\section{III}

Los únicos fragmentos relativamente amplios correspondientes a las Historias que se nos conservan en la actualidad estan constituidos por los discursos y las cartas; de dichos discursos dos en concreto se refieren a la revuelta de Marco Emilio Lépido: el del propio agitador, quien en el año 78 incitó a la plebe a destruir la obra de su predecesor y protector Sila, así como a reivindicar sus derechos ancestrales ${ }^{14}$, y el de su colega y amigo, Lucio Marcio Filipo, quien acusaría a los milicianos de Lépido de haberse convertido en el ejército del crimen, exigiendo la declaración del cónsul revolucionario como enemigo público.

El primer gran acontecimiento al que se refiere Salustio en el libro I de sus Historias ${ }^{15}$ se conecta con el tumultus Lepidi, que tal vez no sería más que un "foco de paja» ${ }^{16}$.

El personaje mencionado en este fragmento no es otro que Marco Emilio Lépido, padre del triúnviro, quien sería elegido cónsul como resultado del apoyo prestado por Pompeyo y tendría como compañero en el consulado a Quinto Lutacio Catulo en el año 78 a.n.e. ${ }^{17}$.

Su cursus honorum se iniciaría con el desempeño del cargo de edil en el momento en que Mario completaba su séptimo consulado. Más tarde se

\footnotetext{
K. BüCHNEF, Sallust, Heidelberg 1960, págs. 121 ss.

Para más detalles ver, como ejemplo, G. Petrone, "Per una ricostruzione del proemio delle Historiae di Sallustio", Pan 4 (1976) 59 ss.

D. GuILBERT, «Salluste, oratio Lepidi consulis et le lle Olynthienne», LEC 25 (1957) 296 ss. 1.55 Maurenbrecher.

16 Terminología utilizada por E. PASOL (Le Historiae e le opere minori di Sallustio, Bolonia 1965, págs. 49-50) de acuerdo con las indicaciones transmitidas por Floro (2.11.1) y Orosio (5.22.18).

Pertenecía a la gens patricia Aemilia, cuyas familias más destacadas fueron las de los Lépidos, los Paulos y los Escauros.
} 
uniría a la política de Sila, enriqueciéndose a través del sistema de las proscripciones ${ }^{18}$ : de esta manera desempeñaria la pretura en Sicilia en el año 81 , convirtiendo su provincia en campo de despojo. Tras la muerte del dictador se pondría nuevamente de lado del partido democrático, tratando entonces de destruir la obra de Sila, cuyo lugar pretendía ocupar sin contar ni con las energías ni con el talento necesarios para ello ${ }^{19}$.

El tono extremadamente violento de dicha exposición en algunas de sus partes ha llevado a poner en duda que Lépido pronunciara el discurso con anterioridad a la muerte de Sila, dadas las circunstancias especiales por las que estaba atravesando la República en aquellos momentos; no obstante, puesto que en esa fecha, o ya había muerto el dictador o se había retirado de la vida política, no existiría impedimento alguno para ello ${ }^{20}$.

En este contexto las palabras pronunciadas por Lépido contra Sila vienen marcadas por una agresividad inusitada, que halla su explicación, no en un ataque contra el colectivo de los ciudadanos romanos, sino más bien en la propaganda a favor de quien pronuncia el discurso.

Como resultado de ello nuestro historiador trataría, a través de las palabras puestas en boca de Lépido, de exacerbar el ánimo popular contra Sila a través de sucesos conocidos solamente a medias, así como mediante la expresión de anhelos incumplidos, etc... intentando granjearse el favor popular hacia quien se presentaba como denunciante público de los efectos perniciosos de la tiranía ${ }^{21}$.

De esta manera Lépido perseguiría con su discurso prevenir a los ciudadanos contra la actitud tiránica de Sila, a pesar de que en el fondo sus deseos se hallaban encaminados más bien hacia la posibilidad de convertirse él mismo en dictador, alcanzando por consiguiente la dirección como caudillo del Estado romano a través del apoyo popular.

\section{IV}

El consulado de Lépido había configurado un hecho de carácter violento en el marco de la República romana: espíritu sedicioso y temperamental, cargado de ambición aunque sin contar con un talento militar sufi-

\footnotetext{
18 Ver capítulo 18 de esta oratio Lepidi.

19 En ese ámbito se contextualiza este discurso demagógico. Cf. A. LA PENNA, "Le Historiae di Saltustio e l'interpretazione della crisi reppublicana", Athenaeum 41 (1963) 213.

20 J. Carcopino, Sylla ou la monarchie manquée, París 1957 (2. ${ }^{\text {a }}$ edic.), pág. 201.

21 J.1. Ciruelo, Salustio. Política e historiografia, Barcelona 1973, págs. 73-75.
} 
ciente, enfrentado por principio a su compañero de consulado, llevaría a cabo una política revolucionaria tratando de beneficiar a la plebe, cuyos favores intentaba conseguir por todos los medios con el fin de asegurar su debilitada situación ${ }^{22}$.

Como consecuencia de ello la revuelta en que se vería involucrada Roma en aquella época alcanzaría la región de Etruria, de forma que los habitantes de Fiésole dieron muerte en masa a los partidarios de Sila, al tiempo que se apoderaron de las tierras que ocupaban con anterioridad.

A ambos cónsules se les asignó entonces por parte del Senado la tarea de aplastar la rebelión; sin embargo, mientras Catulo, una vez finalizada su actividad militar, regresaría a la capital, Lépido no sólo se opuso al licenciamiento de su ejército sino que aumentó sus efectivos con nuevas aportaciones de proscritos de Sila, así como con grupos de etruscos e indeseables de toda clase, a quienes se unieron los cabecillas supervivientes del partido de Mario ${ }^{23}$.

Viéndose fortalecido al contar con tales apoyos, se atrevió a enviar un ultimatum al senado, en el que, entre otras solicitudes, se exigía el derecho de ciudadanía para los cisalpinos, así como la restauración del poder tribunicio, la reintegración de los honores a los proscritos y su reelección para un nuevo consulado.

La asamblea senatorial, apesadumbrada por la intranquilidad generada por la situación planteada en el exterior, estaba dispuesta a entrar en negociaciones cuando Marcio Filipo pronunció contra Lépido el discurso que le atribuye Salustio ${ }^{24}$ : el objetivo del orador estribaba en inducir a dicha asamblea la aprobación del senatusconsultum ultimum contra Lépido en armas y su declaración como enemigo armado, y en consecuencia como no ciudadano ${ }^{25}$.

De esta manera lograría abortar la apatía del Senado hasta el extremo de que el rebelde sería declarado enemigo público, al tiempo que los poderes extraordinarios que reclamaba serían entregados a Apio Claudio, Quinto Catulo y cuantos detentaban el imperium. En consecuencia a Pompeyo se le encomendaría la dirección de la guerra de Módena, siendo encargado Catulo de la defensa de la ciudad ${ }^{26}$.

22 Para más detalles ver, por ejemplo, E. BuRck, «Das Bild der Revolution bei römischen Historikern", Gymnasium 73 (1966) 86 ss.

23 Para más detalles remitimos a R.F. Rossı, "Sulla lota politica in Roma dopo la morte di Silla», PP $20(1965) 133$ ss.

241.77 Maurenbrecher.

25 E. PASOLI, «Privato consilio (e privata arma) in Sallustio», GIF 22.3 (1970) 65 ss.

26 Ante el cariz de la nueva situación Lépido, abatido y maltrecho, se vería obligado a huir a Cerdeña, donde encontraría la muerte en el año 77 a.n.e. 
En este sentido la oratio Philippi parece constituir un verdadero discurso filípico, de acuerdo con lo que demuestran sus numerosos puntos comunes con las Filípicas de Demóstenes y Cicerón ${ }^{27}$; en dicha obra se descubren, por medio del análisis de los recursos y procedimientos estilísticos (especialmente las aliteraciones y cláusulas) empleados por el historiador, una manera de caracterizar a la clase política romana personificada en el orador ${ }^{28}$.

El contenido de esta arenga se corresponde temporalmente casi con el momento histórico posterior al discurso de Lépido; por ello la conexión de los acontecimientos se hace tan estrecha que prácticamente resulta una misma situación observada desde una perspectiva diferente.

Tanto en uno como en otro el Senado romano desempeñó un papel un tanto desangelado, en cualquier caso mucho menos activo e incardinado en los hechos que con respecto a los acontecimientos de Numidia por ejemplo ${ }^{29}$ : en esta oportunidad se vería arrastrado por la enorme fuerza de los populares, quienes a su vez iban a ser explotados por una serie de personajes ambiciosos hasta desembocar, solo algunos años después, en la dictadura de César.

Por ello en un principio todas las ventajas se inclinaban del lado de Lépido, quien por una parte controlaba el poder militar (tanto de los veteranos como de los soldados mercenarios) y por otra contaba con el apoyo de los habitantes de Etruria, quienes se habian rebelado contra la opresión que el Estado romano ejercía sobre ellos en beneficio de la nobleza ${ }^{30}$.

Como consecuencia de ello en modo alguno puede extrañar el hecho de que Salustio, en este caso por boca de Filipo, pase revista a las convulsiones y cambios que se estaban produciendo en el interior de la $\mathrm{Re}$ pública romana y que podemos calificar como subversivos ${ }^{31}$.

Por consiguiente, a manera de síntesis podemos afirmar que ambas arengas constituyen interesantísimos documentos acerca de las respectivas propagandas de los dos partidos políticos rivales en aquellos momentos en la capital del Estado, así como de sus consignas correspondientes, hallándose en el centro de las mismas la controversia sobre la noción de pax pública.

\footnotetext{
27 Para más detalles cf. G. PERL, "Sallusts politische Stellung», WZRostock 18 (1969) 379 ss.

$28 \mathrm{H}$. ROSÉN, «Characterization by Rhetorical Devices in Historiography. The Speech of L.Marcius Philippus in Sallustius' Historiae», Mélanges I. A. Seeligmann, Jerusalen 1983, 1, págs. 539 ss.

29 D.C. EARL, «Sallust and the Senate's Numidian Policy», Latomus 24 (1965) 532 ss.

30 Para más detalles ver N. Santos, La concepción de la historia en Salustio. Oviedo 1997, págs. 109 ss.

J.I. Ciruelo, Salustio. Política e historiografía, págs. 75 ss.
} 
A pesar de todo, la ideología democrática en su estado más puro se halla plenamente representada en el discurso pronunciado por el tribuno de la plebe Licinio Macer en el año 73: coincidiendo con un período de la historia de Roma en el que se estaba llevando a la práctica política la obra de Sila con el objetivo de intentar devolver a la plebe sus antiguos derechos (no podemos olvidar a este respecto que la restauración definitiva del tribunado iba a tener lugar en el año 70), el orador explica el desarrollo de la lucha de clases contemporánea y de los fracasos de la plebe, exalta al mismo tiempo la vis tribunicia, y denuncia finalmente el envilecimiento político y moral en que se veía envuelta la plebe, mostrándose frente a ello como partidario de la no violencia ${ }^{32}$.

Si tenemos en cuenta la cronología del discurso pronunciado por Licinio Macer es posible pensar que tal vez formaría un díptico con el que se nos ha conservado del cónsul Cotta (fechado en el año 74), cuya finalidad estaba dirigida a desviar el descontento popular de su época, centrado básicamente en la crisis de subsistencia provocada por las necesidades tanto exteriores (la actividad de Sertorio en territorio hispano) como interiores (la revuelta de Espartaco) ${ }^{33}$.

En este segundo discurso observamos que el orador demuestra un interés especial en satisiacer las exigencias y necesidades de la plebe: tras los dos decretos sarcionados por el Senado, uno de los cuales autorizaba a los cónsules a proceder a la renovación de los mercados y el otro decidía el traslado a Roma de la contratación de los impuestos sicilianos, que hasta entonces se venían llevando a cabo en la misma provincia ${ }^{34}$, Cotta propondría la abrogación del edicto de Sila que implicaba la incompatibilidad del tribunado de la plebe y del cursus honorum ordinario.

A su muerte el Senado accedería a nuevas concesiones y, bajo la presión popular, los cónsules M.Terencio Varrón, Lúculo y C.Casio Longino garantizaron distribuciones gratuitas de cinco modios de trigo por cabeza y mes, resultando el número de los veneficiados unos 40.000 .

Pese a todo estas concesiones llegarían ya demasiado tarde para ser bien acogidas por parte del pueblo, por lo que a los ojos de los agitadores

32 J. BLÄNSDORF, «Populare Opposition und historische Deutung in der Rede des Volkstribunen Licinius Macer in Sallusts Historien: Zur Ideologie Sallusts und seiner Interpreter", AU 21.3 (1978) 54 ss.

33 G. PERL,, "Die Rede Cottas in Sallusts Historien», Philologus 109 (1965) 75 ss., y 111 (1967) $137 \mathrm{ss}$

34 Medidas todas destinadas a facilitar la recaudación de las contribuciones en especie con el fin de favorecer el avituallamiento de la capital. 
de la plebe esta solución se consideró como un mecanismo inventado por el partido de los nobles con el objetivo de mantenerlos a raya ${ }^{35}$.

Estos sentimientos son los que deja traslucir el discurso de Gayo Licinio Macer ${ }^{36}$, padre del orador Licinio Calvo, ante la plebe: después de hacer alusión a las diversas peripecias y enfrentamientos derivados del conflicto de los últimos años entre aristócratas y plebeyos, nos muestra la futilidad de las ventajas obtenidas por la plebe y la voluntad constante de los nobles por mantenerla bajo su poder y conservar todos sus privilegios.

En el epílogo recomienda a sus oyentes sacudirse la apatía, recurriendo para ello al arma más poderosa con que contaban en sus manos, la negativa al servicio militar, en tanto no lograran recuperar íntegramente el poder tribunicio, única defensa de su libertad ${ }^{37}$.

De esta manera el discurso que el historiador de Amiterno pone en boca de Licinio Macer en el año 73, con el objetivo de incitar a los componentes de la plebe a una acción decisiva en favor de la restitución del poder tribunicio, en gran medida respondería al pensamiento político de Salustio, aunque se detecten en él deformaciones de partido.

En cualquier caso es posible considerar este discurso de signo contrario al pronunciado por Cotta, a pesar de que ambos se hallan dirigidos a la plebe en un nivel estrictamente demagógico: mientras que el del cónsul trataba de lograr la pacificación de los ánimos populares y su encauzamiento hacia el gobierno, el de Licinio Macer se refiere a la apatía del pueblo, exhortando a sus componentes a la disconformidad y poniendo al descubierto los mecanismnos de dominio utilizados por la nobleza romana ${ }^{38}$.

Tomando como punto de referencia la libertad y hechos gloriosos de los antepasados, la situación se centrará en los problemas socio-económicos de la época, haciendo sobresalir las dificultades económicas vinculadas al abastecimiento de víveres a la capital y un principio de reforma tributaria de acuerdo con el cual desde el sur de Italia llegarian provisiones más abundantes destinadas a garantizar las entregas gratuitas de trigo a la plebe como parte de la liberalidad del Estado ${ }^{39}$.

\footnotetext{
35 Puesto que, al recibir lo justo para no morir de hambre, les mantendría en la debilidad mientras sesteaban en un deambular vital oscuro y sin esperanza.

Hist 3.48 Maurenbrecher

37 Más detalles en J. BLÄNSDORFF, «Populare Opposition und historische Deutung in der Rede des Volkstribunen Licinius Macer in Sallusts Historien", págs. 59 ss.

38 J.I. Ciruelo, Salustio. Política e historiografia, pág. 79.

39 Oratio Macri 19.
} 
En este contexto se comprende la exigencia por parte del pueblo del restablecimiento del poder tribunicio, que había sido abolido en tiempos de la dictadura de Sila, ensalzando el recuerdo y esfuerzo de los antepasados, quienes se habian visto obligados a retirarse hasta lograr la salvaguarda de sus derechos (cap. 1); junto a ello el orador incita al pueblo a la resistencia pasiva como arma arrojadiza contra los optimates (oligarcas) con el fin de lograr el respeto y reconocimiento de los mismos (capítulos 17-18).

\section{VI}

Algún tiempo antes (año 75) se pronunciaría el discurso dirigido por C.Cotta al conjunto del pueblo romano, en el que se sacan a la luz claramente los condicionantes sociales y políticos que atenazaban a Roma tras la aventura de Lépido, lo que traería consigo el intento revolucionario de la plebe por recuperar sus derechos; este planteamiento se halla cargado de una habilidad oratoria enormemente remarcada en palabras de Cicerón ${ }^{40}$.

Las revueltas que siguieron al consulado de Lépido, unido a la guerra contra Sertorio en Hispania y a la de Espartaco en territorio itálico, habían acarreado en Roma una carestía de los productos; por otra parte esto redundó en que el pueblo se rodease de un estado de marasmo, agitación y descontento.

De inmediato Creo Sicinio, que había tomado partido por la política demagógica de Lépido, reclamaría la restauración del tribunado con todas sus implicaciones; en tales circunstancias fue elegido cónsul en el año 75 C. Aurelio Cotta en compañía de Lucio Octavio ${ }^{41}$.

Tanto Cotta como su colega en el consulado tratarían de llevar a cabo una política de fuerza y conciliación a un mismo tiempo: de esta manera, por ejemplo, al tribuno Quinto Opimio, que había reivindicado su derecho a la intercessio abolida por Sila, no sólo no le fue concedido ese favor sino que lograron, además, la condená y confiscación de sus bienes.

En este sentido nuestro personaje pondría todo su esfuerzo, a través de un discurso de caracteres patéticos ${ }^{42}$, en hacer comprender al conjunto del pueblo los motivos que le habían conducido a la miseria que en esos momentos le oprimía y de la que el gobierno de la República no podía ser considerado como responsable.

40 Brutus 202

41 J. MALITZ, «C. Aurelius Cotta cos. 75 und seine Rede in Sallusts Historien», Hermes 100 (1972) $359 \mathrm{ss}$.

42 Hist. 2.47 Maurenbrecher. 
En dicha arenga se mencionan igualmente los servicios prestados al Estado y al pueblo, así como la devoción prestada tanto a los ciudadanos como a la República, hasta el extremo de que se ofrecería en sacrificio, si llegara el caso, por la salvación de todos.

Nos encontramos, sin duda, ante el alegato más corto y vacio de contenido de cuantos conservamos de los correspondientes a los fragmentos de las Historias salustianas; en cualquier caso se identifica, como han observado ya algunos investigadores ${ }^{43}$, con el discurso característico de un político en situación comprometida y que necesita cuanto antes congraciarse con la opinión pública en pro de sus objetivos.

En otros términos, a pesar de que se ha pretendido ver en el discurso de Coatta un intento por subrayar una situación dramática y peligrosa, junto con las circunstancias miserables y caóticas que envolvían al colectivo popular, así como el deterioro de la autoridad estatal, en parte como consecuencia de factores externos ${ }^{44}$, en el fondo no sería más que un recurso secundario si lo comparamos con la intención de dibujar el retrato de un hombre ambicioso, pese a su debilidad, que buscaba abiertamente obtener el favor popular escudándose en tonos patéticos.

Este documento literario, plagado de tópicos, a veces camuflados, recuerda a los ciudadanos romanos que en sus manos yacía la posibilidad de elegir a los magistrados (en este caso el consulado que Cotta desempeña), resaltando precisamente el hecho de que la suya en concreto se había producido en circunstancias extremadamente difíciles, por lo que no se le podrán exigir excesivas responsabilidades en el caso de que los acontecimientos no llegasen a realizarse satisfactoriamente para todo el colectivo de ciudadanos ${ }^{45}$.

\section{VII}

Los dos restantes fragmentos conservados de las Historias de Salustio (en este caso no del género oratorio sino epistolar) corresponden a la misiva dirigida por Pompeyo al Senado, en la que se solicita con premura ayuda económica y militar para llevar a cabo la guerra contra Sertorio en Hispania ${ }^{46}$, y la carta dirigida por Mitrídates a Arsaces, en la que el rey del

\footnotetext{
${ }_{43}$ Ver, por ejemplo, J.J. Ciruelo, Salustio. Politica e historiografía, pág. 77.

44 Ver, por ejemplo, G. PERL, "Die Rede Cottas in Sallusts Historien", Philologus 109 (1965) 75 ss.

${ }_{45}$ Más detalles y pormenores en J. MaLiTZ, "C. Aurelius Cotta cos. 75 und seine Rede in Sallusts Historien», págs. 359 ss.

${ }_{46}$ Para más detalles cf. P. FrassinetTI, «I fatti di Spagna nel libro II delle Historiae di Sallustio", Studurb 49.1 (1975) 381ss.
} 
Ponto acusa con desmedida virulencia la opresión que supone el imperialismo romano ${ }^{47}$.

El documento epistolar atribuido a Pompeyo y dirigido al Senado nos presenta con claridad tanto las circunstancias como el alcance de la situación política general por la que atravesaba el Estado romano en aquellos momentos ${ }^{48}$ : atemorizados ante el progresivo avance de Sertorio en territorio hispano (donde contaría además con la adhesión de celtíberos y lusitanos) y ante la amenaza de su regreso a Italia, los senadores confiaron la dirección de las operaciones bélicas en el año 77 a Pompeyo, quien había dado muestras ya de sus cualidades militares en la victoria obtenida contra Lépido.

De esta manera, apoyándose en su lugarteniente Fonteyo, iniciaría con rapidez la campaña: en un plazo de apenas 40 días lograría reclutar un ejército en italia, franquear los Alpes y, tras asignar a su compañero la tarea de pacificar la provincia Narbonense, penetrar en suelo hispano en la primavera del año $76{ }^{49}$. Los combates se hicieron encarnizados como consecuencia de lo escabroso del terreno, sin olvidar el hecho de que Sertorio era un adversario valeroso y hábil, que además se veía respaldado por los indígenas hispanos, quienes resistían con una gran energía.

La situación en Roma no se presentaba favorable: de acuerdo con lo que se desprende del discurso de Cotta la capital, empobrecida y amenazada por el hambre, no pudo remitir al ejército pompeyano ni avituallamiento ni dinero para la soldada, lo que provocó que los militares, hambrientos y desmoralizados, estuvieran cerca de rebelarse o regresar a Italia ${ }^{50}$.

Ante esta situación casi angustiosa, las continuas demandas de Pompeyo quedaban sin respuesta; por ello, desesperado ante la aparente apatía e indiferencia del Senado, el general remitió esta misiva, en la que, tras hacer alusión a sus servicios pasados a la República y a sus reclamaciones anteriores, amenaza con trasladar a Italia el escenario de la guerra civil.

47 Ver, entre otros, E. BIKERMANN, «La lettre de Mithridate dans les Histoires de Salluste», REL 24 (1946) 131 ss.

48 Esta carta (Hist. 2.98 Maurenbrecher) se fecha durante el consulado de Cotta y Octavio.

49 Para más detalles remitimos a J.M. ROLDÁN, «La guerra civil entre Sertorio, Metelo y Pompeyo», Historia de España antigua, II: España romana, Ed.Cátedra, Madrid 1978, págs. 125 ss.

50 J.M. Solana y A. Montenegro, Historia de España, 3: España romana, Ed.Gredos, Madrid 1986, págs. 111-112. 
La carta pompeyana sería objeto de deliberación en sesión plenaria celebrada por el Senado en la primavera del año 74; como resultado de ello los nuevos cónsules, Lucio Lúculo y Marco Cotta, se esforzarían con rapidez en satisfacer las demandas del general romano ${ }^{51}$.

En este sentido la historiografía antigua ha logrado esclarecer, a través de informaciones menos directas pero mucho más abundantes, estos mismos sucesos; sobresalen ante todo las referencias a la figura de Pompeyo, personaje sobre el que la gran mayoría de las noticias estan conectadas con la personalidad y la carrera militar de César ${ }^{52}$.

La misiva pompeyana trataba fundamentalmente de solicitar fondos (víveres y soldada) del Senado para lograr el mantenimiento del ejército que la propia institución senatorial le había encomendado con el objetivo de hacer frente a Lúculo y Sertorio.

Así pues, recurriendo a una terminología casi patética, el autor de la carta trata de impresionar a los senadores mediante el recuerdo de sus anteriores servicios a la patria, de su continua fidelidad al Estado, de las victorias por él logradas en favor del pueblo romano y de las necesidades derivadas de la campaña militar cuyo frente le habían encomendado, resaltando especialmente el hecho de que era preciso dar solución inmediata a la penuria que atenazaba al ejército ${ }^{53}$.

Es por ello que, ante la amenaza inminente y un hipotético motín de los integrantes de las legiones ${ }^{54}$, el Senado convoca a los cónsules Lúculo y Cotta con el fin de que se de cumplimiento lo más rápidamente posible a la solicitud de Pompeyo.

De cualquier forma, la hostilidad puesta de manifiesto por Salustio con respecto a este personaje parece obedecer a múltiples motivos: por un lado a la posibilidad de criticar a través de él, sin demasiados riesgos, a Octavio, así como la irritación contra un ser profundamente desleal y, por último, el resentimiento personal del eterno perdedor frente al triunfador nato, que con una facilidad pasmosa parece ganar tanto los corazones de sus conciudadanos como las confrontaciones con sus enemigos ${ }^{55}$.

\footnotetext{
51 Los detalles de los acontecimientos aparecen recogidos en P. FrassInETTI, «l fatti di Spag. na nel libro II delle Historiae di Sallustio", págs. 381 ss.

52 A. Ernout, Salluste. Catilina, Jugurtha, Fragments des Histoires, pág. 273.

53 Sobre estas cuestiones remitimos a J.I. CIRUELO, Salustio. Política e historiografía, pp.78-79.

54 Cap. 10.

55 Una revisión de los hechos que confirman esto la encontramos en B.R.KATZ, "Sallust and Pompey", RSA 12 (1982) 75 ss.
} 


\section{VIII}

Finalmente la carta dirigida por Mitrídates al rey de los partos, Arsaces, que posiblemente nuestro historiador redactaría teniendo ante sus ojos un documento auténtico, esta muy lejos de representar una alternativa seria a la filosofía oficial de la política romana; en realidad no se trata más que de una deformación casi completa de la verdad histórica bajo el pretexto de la rapacidad y el antirrealismo como móviles exclusivos de la expansión romana por todo el mundo conocido ${ }^{56}$.

El rey del Ponto soslaya las apetencias y objetivos que en realidad perseguía (los profundos deseos de poder y de riquezas que enmascaraban todos sus actos) para presentarnos una visión parcial acerca de la penetración de los romanos en Asia; en ese contexto observamos que su argumentación coincide totalmente con el proceso intentado contra el imperialismo romano por parte de los populares, entre quienes se alineaba el propio Salustio ${ }^{57}$.

Este último fragmento con entidad de las Historias salustianas ${ }^{58}$ se conecta con los acontecimientos correspondientes a la tercera guerra contra Mitrídates: tras los éxitos logrados en un primer momento en su ofensiva contra los romanos (invasión de Capadocia y recuperación de Bitinia), el monarca del Ponto iba a encontrar en Lúculo a un adversario terrible, que le infligiría una primera derrota en Cícico, a resultas de la cual le obligaría a retirarse con graves pérdidas.

Como resultado de ello abandonaría Bitinia, de manera que, amparado únicamente en la lentitud de Voconio, retrasado en Samotracia, pudo huir con su flota al Bósforo, zozobrando por causa de una tempestad en el viaje de regreso a su reino una parte de sus vasallos ${ }^{59}$.

Atacado de nuevo por las fuerzas romanas, se refugiaría en Armenia bajo la protección de su suegro Tigranes en el año 72: entonces Lúculo, tras haber concedido un descanso a sus tropas, negociará con Tigranes, por medio de su cuñado Apio Claudio, la extradicción de Mitrídates. Ahora

56 Ver, por ejemplo, L. RADITSA, «The Historical Context of Mithridates Description of the Status of Asia in Sallust's Letter of Mithridates", Helikon 9-10 (1969-1970) 689 ss.

57 Estas cuestiones aparecen tratadas con mucha mayor amplitud en L. RADITSA, "Mithridates's View of the Peace of Dardanus in Sallust's Letter of Mithridates", Helikon 9-10 (1969-1970) 632 ss.

$58 \quad 4.60$ Maurenbrecher.

59 Los pormenores de estos hechos se describen en E. MARótI, «Die Rolle der Seeräuber in der Zeit der Mithridatischen Krieg", Ricerche storiche ed economiche in memoria di Corrado Barbagallo, Nápoles 1970, 1, págs. 481 ss. 
bien, tras el fracaso continuado de unas prolongadas negociaciones, el general romano reaunuda la guerra y en octubre del 69 derrota a Tigranes en Tigranocerta ${ }^{\hat{0}}$.

Mitrídates entonces, agotado por la larga y dura guerra que había venido sosteniendo, buscaría continuar los combates apoyándose en alianzas, para lo que entablaría conversaciones con el rey de los partos (Phraates III o Arsaces XII), lo que constituye el contenido del presente mensaje epistolar ${ }^{61}$.

Preocupado por los avances de Tigranes en Mesopotamia y anhelando hacer pagar su apoyo a los romanos, Arsaces decidió conservar la neutralidad; $y$ en esa situación permaneció hasta el momento en que los éxitos de Pompeyo le inclinaron a ponerse de su parte, ya en el año $66^{62}$.

Así pues, la crítica expresada en esta carta por el rey del Ponto contra los romanos (en concreto contra su imperialismo), que podría ser válida en el caso de que no se presentase tan recargada, sirve a nuestro historiador para caracterizar al soberano bárbaro con ideas y conceptos falsificados por el odio y la mala fe ${ }^{63}$.

Poniéndose en el lugar que corresponde a Mitrídates, el autor pasa revista a las líneas de actuación de la política romana en el exterior, lo que le permitirá por otro lado expresar con mayor libertad sus opiniones al ser puestas en boca de un enemigo de Roma.

No puede extrañarnos, por tanto, que el monarca bárbaro acumule, a lo largo de toda la carta, acusación tras acusación contra los romanos, por un lado como denuncia de la conducta del Estado y la administración y por otro como medio de atemorizar al destinatario del escrito y conseguir así su alianza ${ }^{64}$.

Ahora bien, algunos investigadores actuales consideran que la carta de Mitrídates del Ponto no sería más que una invención de Salustio, desarrollando en la misma dicho autor un proceso de persuasión que le con-

\footnotetext{
60 J.M. Rolóan, Historia de Roma, Salamanca 1995, pág. 224.

61 Como contrapartida simultáneamerite el delegado de Pompeyo, Sextilo, trataba de enrolar a) rey persa en la alianza romana.

62 Un desarrollo pormenorizado de los hechos en E. OLSHAUSEN, "Mithridates VI und Rom", ANRW 1.1 (1972) $806 \mathrm{ss}$

63 H.E. STIER, "Der Mithridatesbrief aus Sallusts Historien als Geschichtsquelle", Festschrift F.Altheim, Berlín 1969, págs. 441ss.

64 Capítulos 15 y 17. Para más detalles remitimos a J.I. CiRuelo, Salustio. Política e historiografia, págs. 80-81. Ver igualmente R. Goossens, "Les Kittim du Commentaire d'Habacuc", NClio 4 (1952) 137 ss.
} 
duce progresivamente a su objetivo: hacer tomar a Arsaces la decisión de entrar en conflicto con los enemigos de Roma ${ }^{65}$.

Desde un punto de vista compositivo y expresivo esta carta puesta en boca de Mitrídates resulta perfecta, confirmándonos la madurez artística del historiador: el rey del Ponto aparece ante nosotros como un maestro en el arte de la deformación histórica y extremadamente hábil en el momento de presentar a Arsaces los motivos que le inducirían a enfrentarse con los romanos sin darle en ningún momento la impresión de querer influir directamente en su decisión.

\section{CONCLUSIONES}

Ante todo observamos que Salustio, a lo largo de los fragmentos conservados de sus Historias (discursos y cartas principalmente), ha analizado, despiadada y expresivamente a un mismo tiempo, la crisis que atenazaba a las instituciones de la República romana en aquella época; de esta manera, abandonando la monografía por la narración continuada, el autor de Amiterno da comienzo a dicha obra con los acontecimientos del año 78 , a renglón seguido por tanto de la muerte de Sila.

De un modo simiiar a lo que podemos observar en el caso de La conjuración de Catilina y La guerra de Yugurta, aunque mucho más extensamente, trata de investigar las causas lejanas de los acontecimientos, utilizando para ello una perspectiva racionalista y pesimista a un mismo tiempo ${ }^{66}$.

Este tipo de análisis, en el que posteriormente se apoyará san Agustín para demostrar que el cristianismo en modo alguno sería responsable de la decadencia de Roma ${ }^{57}$, acabaría por convertir al régimen silano en el prototipo de actividad política que da paso al inicio de la decadencia de las estructuras republicanas.

Sería, sin embargo, la expansión territorial del Estado romano la representante del comienzo de la decadencia interior, destacando como aspectos más significativos de la misma la corrupción generalizada de la

65 En este sentido ver F. AHLHEID, “Oratorical Strategy in Sallust's Letter of Mithridates reconsidered", Mnemosyne 41 (1988) 67 ss.

66 K. VRETSKA, «Bemerkungen zum Bau der Charakteristik bei Sallust», SO 31 (1955) 105 ss.

67 Ver, entre otros, G. BONAMENTE, «ll metus Punicus e la decadenza di Roma in Sallustio, Agostino ed Orosio», GIF 27 (1975) 137 ss. 
sociedad, la lucha encarnizada entre los potentes y la plebe, el desencadenamiento desmesurado de la avaritia y la ambitio, la ambigüedad puesta de manifiesto en ocasiones incontables por parte de los ciudadanos honrados, etc... ${ }^{68}$.

En lo que concierne al estilo utilizado para este tipo de descripciones por parte del historiador, además de sus consabidas características de arcaísmo, los fragmentos de esta obra salustiana rezuman influencias de Catón, tal vez como contrapunto a la prosa de Cicerón y César; de esta manera, al avance y aproximación del pensamiento hacia un pesimismo sin esperanza corresponde un lugar cada vez más destacado de la lengua y del estilo ${ }^{69}$.

En este sentido a través del análisis de los discursos de Salustio, César, Tito Livio y Tácito es posible observar que las palabras no constituian meros artificios decorativos sino elementos muy importantes para presentar clara y ostensiblemente los rasgos propios del carácter de un personaje ${ }^{70}$, o bien una situación o una opinión que los historiadores deseaban que fueran destacadas, pudiendo ofrecer al mismo tiempo sus propias interpretaciones de los hechos ${ }^{71}$.

Así pues, si en las monografías salustianas descubrimos un enfoque claramente biográfico, puesto que nos presenta una visión histórica que arranca de los personajes implicados directamente en los acontecimientos, en los discursos y cartas de las Historias dichos personajes no se manifiestan más que como simples narradores de ese devenir de acontecimientos en los que se habían visto envueltos de una u otra manera.

Es por ello que este conjunto de narraciones en realidad no son biografías, pudiéndose considerar a lo sumo únicamente como una biografía de Roma, pero en ningún caso de los personajes concretos que tomarían parte en su historia ${ }^{72}$.

Finalmente por lo que nos es posible juzgar a través de tales testimonios hemos de concluir que el historiador de Amiterno parece haber

68 Más detalles sobre este particular en E. PASOLi, «Pensiero storico ed espressione artistica nelle Historiae di Sallustio», BPEC 14 (1966) 23ss.

69 D. FLACH, «Die Vorrede zu Sallusts Historien in neuer Rekonstruktion», Philologus 117 (1973) 76 ss.

70 E. LösTEDT, Roman Literary Portraits, Oxtord 1958, págs. 93ss.

71 Para profundizar en estos temas remitimos, entre otros, a N.P. MILLER, «Dramatic Speech in the Roman Historians", G\&R 22 (1975) 45ss.

72 En otras palabras, en los fragmentos de las Historias de Salustio encontramos, por consiguiente, casi meros reportajes históricos. Cf. J.l. Cinuelo, Salustio. Política e historiografía, pág. 81 . 
mostrado en la elaboración de las Historias la misma severidad por el partido aristocrático y la misma misantropía que en el resto de sus obras $^{73}$.

En cualquier caso, no debemos olvidar que esta serie de menciones y referencias resultan demasiado breves e incoherentes para poder formarnos, exclusivamente a partir de ellas, una idea apropiada y convincente de lo que en realidad supondrían las Historias de Salustio ${ }^{74}$.

73 Así se manifiesta, por ejemplo, en el primero de los fragmentos (Hist. I, fragm. 12 Maurenbrecher) que conservamos de la misma. Cf. L. ALFONSI, «Sul metus Punicus Sallustianus», Athenaeum 51 (1973) 383-384.

74 Solamente en las cartas contenidas en el Vaticano 3864 es posible observar todas las cualidades literarias anteriormente apuntadas. 